\title{
Solution processed Lanthanum Aluminate gate dielectrics for use in Metal Oxide-Based thin film transistors
}

\author{
M. Esro ${ }^{1}$, R. Mazzocco 2 , G. Vourlias ${ }^{3}$, O. Kolosov ${ }^{2}$, A. Krier ${ }^{2}$, W. I. Milne ${ }^{4,5}$ and G. \\ Adamopoulos ${ }^{1, \mathrm{a})}$ \\ ${ }^{1}$ Lancaster University, Engineering Department, Lancaster LA1 4YR, UK \\ ${ }^{2}$ Lancaster University, Physics Department, Lancaster, LA1 4YB, UK \\ ${ }^{3}$ Physics Department, Aristotle University of Thessaloniki, 54124 Thessaloniki, GREECE \\ ${ }^{4}$ Department of Engineering, University of Cambridge, 9 JJ Thomson Avenue, Cambridge CB3 0FA, UK \\ ${ }^{5}$ Department of Electrical and Computing Engineering, University of Canterbury, 4800 Christchurch, NEW \\ ZEALAND
}

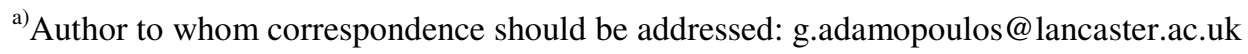

\begin{abstract}
We report on $\mathrm{ZnO}$-based thin-film transistors employing lanthanum aluminate gate dielectrics $\left(\mathrm{La}_{\mathrm{x}} \mathrm{Al}_{1-\mathrm{x}} \mathrm{O}_{\mathrm{y}}\right)$ grown by spray pyrolysis in ambient atmosphere at $440{ }^{\circ} \mathrm{C}$. The structural, electronic, optical, morphological and electrical properties of the $\mathrm{La}_{\mathrm{x}} \mathrm{Al}_{1-\mathrm{x}} \mathrm{O}_{\mathrm{y}}$ films and devices as a function of the lanthanum to aluminium atomic ratio were investigated using a wide range of characterization techniques such as UV-visible absorption spectroscopy, impedance spectroscopy, spectroscopic ellipsometry, atomic force microscopy, $\mathrm{x}$-ray diffraction and field-effect measurements. As-deposited $\mathrm{LaAlO}_{\mathrm{y}}$ dielectrics exhibit a wide band gap $(\sim 6.18 \mathrm{eV})$, high dielectric constant $(k \sim 16)$, low roughness $(\sim 1.9 \mathrm{~nm})$, and very low leakage currents $\left(<3 \mathrm{nA} / \mathrm{cm}^{2}\right)$. TFTs employing solution processed $\mathrm{LaAlO}_{\mathrm{y}}$ gate dielectrics and $\mathrm{ZnO}$ semiconducting channels exhibit excellent electron transport characteristics with hysteresis-free operation, low operation voltages $(\sim 10 \mathrm{~V})$, high on/off current modulation ratio of $>10^{6}$, subthreshold swing (SS) of $\sim 650 \mathrm{mV} \mathrm{dec}^{-1}$ and electron mobility of $\sim 12 \mathrm{~cm}^{2} \mathrm{~V}^{-}$ ${ }^{1} \mathrm{~s}^{-1}$
\end{abstract}


Solution-processed film stacks constitute a promising alternative to conventional vapor deposition for large area applications as they could provide a breakthrough in manufacturing cost. In that respect and given the recent advances in metal oxide semiconductors deposited by vacuum-based techniques, solution processed devices offers an alternative approach by marrying fabrication simplicity with high-throughput manufacturing. Whilst progress on solution-processed oxide semiconductors has been rapidly advancing, research efforts towards the development of dielectric materials has been relatively slow, with most of the reported work performed using conventional dielectrics based on $\mathrm{SiO}_{2}$ that usually results in high voltage transistor operation and hence increased power consumption. To tackle this problem, different approaches have been explored including the use of ultra-thin nanodielectrics, ${ }^{1}$ electrolyte gate dielectrics ${ }^{2}$, and high- $k$ dielectrics. Among these, the use of high- $k$ dielectrics is arguably the most attractive option since it can enable low leakage currents, through the use of physically thicker films, as well as low-voltage operation. There are already numerous candidate materials such as transition metal oxides i.e. $\mathrm{TiO}_{2}{ }^{3} \mathrm{ZrO}_{2}{ }^{4}$ $\mathrm{HfO}_{2},{ }^{5}$ silicates, ${ }^{6,7}$ and phosphates ${ }^{8}$ that could potentially replace $\mathrm{SiO}_{2}$. Additionally, rare earth metal oxides such as $\mathrm{La}_{2} \mathrm{O}_{3}, \mathrm{Y}_{2} \mathrm{O}_{3}, \mathrm{Pr}_{2} \mathrm{O}_{3}$ have also been considered as potential high- $k$ gate dielectrics alternatives to $\mathrm{SiO}_{2}$. Amongst them lanthanum oxide $\left(\mathrm{La}_{2} \mathrm{O}_{3}\right)$, with a $k$ of about 27 and a large band gap $(\sim 6 \mathrm{eV})$ is being considered as the most promising gate dielectric. However, there are still many issues with $\mathrm{La}_{2} \mathrm{O}_{3}$ that are related to poor interface properties, and chemical instability as it readily converts to $\mathrm{La}_{2}\left(\mathrm{CO}_{3}\right)_{3}$ and $\mathrm{La}(\mathrm{OH})_{3}$ during growth or upon annealing, ${ }^{9,10}$ or reacting with ambient water. ${ }^{11}$

An obvious solution to this problem is the use of alloy forms or complex oxides where a combination of the desirable electrical and optical properties can be tailored by exploiting the properties of different component oxides. ${ }^{12}$ To this end, $\mathrm{LaAlO}_{3}$, which is a compound of $\mathrm{La}_{2} \mathrm{O}_{3}$ and $\mathrm{Al}_{2} \mathrm{O}_{3}$, shows high immunity against environmental moisture, 
thermal stability similar to that of $\mathrm{La}_{2} \mathrm{O}_{3}$, high dielectric constant in the range between 25 and $27^{13}$ and high optical band gap (5.6 eV for crystalline $\mathrm{LaAlO}_{3}$ and $6.2 \mathrm{eV}$ for amorphous $\left.\mathrm{LaAlO}_{3}\right)^{14,15}$

$\mathrm{LaAlO}_{3}$ thin films have been deposited on a variety of substrates using a number of vacuum based techniques including atomic layer deposition (ALD), ${ }^{16-18}$ molecular beam epitaxy (MBE), ${ }^{19,} 20$ pulsed laser deposition (PLD), ${ }^{21,22}$ RF sputtering, ${ }^{23,24}$ and metal organic chemical vapor deposition (MOCVD). ${ }^{25-27}$

However despite their attractive properties and extraordinary performance, vacuumbased deposition techniques still suffer from high manufacturing cost and incompatibility with large area deposition. In order to overcome this technology bottleneck, significant research has been focused on the development of alternative solution processing deposition methods such as spray pyrolysis ${ }^{28-31}$ and sol-gel. ${ }^{32-34}$

Here we study the structural, optical, electronic and dielectric properties of $\mathrm{La}_{\mathrm{x}} \mathrm{Al}_{1-\mathrm{x}} \mathrm{O}_{\mathrm{y}}$ gate dielectrics grown by spray pyrolysis in ambient air as a function of the lanthanum to aluminium atomic ratio. Lanthanum to aluminum atomic ratio was adjusted by the simple physical blending of the soluble precursors in alcohol and dimethylformamide-based solutions. We also demonstrate their implementation in high-mobility TFTs based on $\mathrm{ZnO}$ semiconducting channels similarly grown by spray pyrolysis ${ }^{35}$. The electronic and morphological properties of $\mathrm{La}_{\mathrm{x}} \mathrm{Al}_{1-\mathrm{x}} \mathrm{O}_{\mathrm{y}}$ layers are investigated using a range of techniques including atomic force microscopy (AFM), UV-Vis absorption spectroscopy, admittance spectroscopy, spectroscopic ellipsometry, and x-ray diffraction (XRD). Finally, the electron mobility of the spray coated $\mathrm{ZnO}$ films employing $\mathrm{La}_{\mathrm{x}} \mathrm{Al}_{1-\mathrm{x}} \mathrm{O}_{\mathrm{y}}$ gate dielectrics was investigated using an optimized bottom gate, top-contact transistor architecture. 
$\mathrm{La}_{\mathrm{x}} \mathrm{Al}_{1-\mathrm{x}} \mathrm{O}_{\mathrm{y}}$ thin films were deposited by spray pyrolysis at a substrate temperature of $440{ }^{\circ} \mathrm{C}$ in air. Commercially available indium tin oxide (ITO) coated glass substrates acting as the gate electrode were placed onto a hotplate and (3:1) methanol and dimethylformamide solutions blends $(0.1 \mathrm{M})$ of lanthanum(III) 2,4-pentanedionate $\mathrm{La}\left(\mathrm{C}_{5} \mathrm{H}_{7} \mathrm{O}_{2}\right)_{3}$ and aluminum 2,4-pentanedionate $\mathrm{Al}\left(\mathrm{C}_{5} \mathrm{H}_{7} \mathrm{O}_{2}\right)_{3}$ were sprayed onto them as aerosols using a conventional pneumatic airbrush. $\mathrm{ZnO}$ semiconducting channels thin films were sprayed subsequently from a methanol solutions of zinc acetate $\mathrm{Zn}\left(\mathrm{CH}_{3} \mathrm{COO}\right)_{2}$ at a substrate temperature of $400{ }^{\circ} \mathrm{C}$. The dielectric properties of the as-processed $\mathrm{La}_{\mathrm{x}} \mathrm{Al}_{1-\mathrm{x}} \mathrm{O}_{\mathrm{y}}$ thin films were investigated using a standard metal-insulator metal (MIM) configuration with aluminum contacts evaporated through a shadow mask on top of glass/ITO/La $\mathrm{Al}_{1-\mathrm{x}} \mathrm{O}_{\mathrm{y}}$ stacks. Similarly, aluminum metal source and drain electrodes were thermally evaporated under high vacuum $\left(10^{-6}\right)$ through a shadow mask following $\mathrm{ZnO}$ deposition on the $\mathrm{ITO} / \mathrm{La}_{\mathrm{x}} \mathrm{Al}_{1-\mathrm{x}} \mathrm{O}_{\mathrm{y}}$ gate structures resulting in bottom-gate top-contact transistors with a channel width $\mathrm{W}$ of $1000 \mu \mathrm{m}$ and channel length $\mathrm{L}$ in the range of $20-100 \mu \mathrm{m}$. Electrical measurements were performed under vacuum at $10^{-6}$ mbar.

Optical transmission spectra of $\mathrm{La}_{\mathrm{x}} \mathrm{Al}_{1-\mathrm{x}} \mathrm{O}_{\mathrm{y}}$ films on fused silica substrates were measured at wavelengths between 200 and $1000 \mathrm{~nm}$ using a Perkin Elmer lambda 35 UV-Vis spectrophotometer. A set of Tauc plots of $\mathrm{La}_{\mathrm{x}} \mathrm{Al}_{1-\mathrm{x}} \mathrm{O}_{\mathrm{y}}$ films as a function of the $\left[\mathrm{La}^{3+}\right] /\left[\mathrm{La}^{3+}+\mathrm{Al}^{3+}\right]$ atomic ratio are shown in Figure 1(a). The optical band gap evolution as a function of the $\left[\mathrm{La}^{3+}\right] /\left[\mathrm{La}^{3+}+\mathrm{Al}^{3+}\right]$ ratio is illustrated in Figure 1(b) and is in good agreement with the values reported in the literature for solution processed $\mathrm{La}_{2} \mathrm{O}_{3}$ and $\mathrm{Al}_{2} \mathrm{O}_{3}$ dielectrics.

The optical band gap (direct) shows a monotonic decrease with increase in the $\left[\mathrm{La}^{3+}\right] /\left[\mathrm{La}^{3+}+\mathrm{Al}^{3+}\right]$ atomic ratio and varies between the $5.5 \mathrm{eV}$ for $\mathrm{La}_{2} \mathrm{O}_{3}$ and the $6.4 \mathrm{eV}$ for spray-deposited $\mathrm{Al}_{2} \mathrm{O}_{3}$ respectively. The band gap value of the $\mathrm{LaAlO}_{\mathrm{y}}\left(\left[\mathrm{La}^{3+}\right] /\left[\mathrm{Al}^{3+}\right]: 1\right.$, stoichiometric thereafter) dielectric $(\sim 6.18 \mathrm{eV})$ complies with the band offset condition ${ }^{36}$ 
which requires a dielectric of reasonably large band gap (potential barrier at each band $>1$ $\mathrm{eV}$ ) in order conduction into the dielectric's bands by the Schottky emission of electrons or holes of the $\mathrm{ZnO}$ semiconducting channel to be inhibited ( $\mathrm{ZnO}$ band gap $\sim 3.3 \mathrm{eV}$ ).

Additionally, the Urbach tail energy $\left(\mathrm{E}_{\mathrm{u}}\right)$ of $\mathrm{La}_{\mathrm{x}} \mathrm{Al}_{1-\mathrm{x}} \mathrm{O}_{\mathrm{y}}$ films as illustrated in Figure 1(c) exhibits a monotonic decrease with increase in the $\left[\mathrm{La}^{3+}\right] /\left[\mathrm{La}^{3+}+\mathrm{Al}^{3+}\right]$ ratio. The latter can be attributed to a decrease of the dynamic disorder (exciton-phonon coupling) which is expected with increase in the lanthanum content and the formation of $\mathrm{La}_{2} \mathrm{O}_{3}$ nanocrystals. To note that the $\mathrm{X}$-axis error bars correspond to the La:Al ratio obtained by Energy-dispersive X-ray spectroscopy (EDS) experiments on selected $\mathrm{La}_{\mathrm{x}} \mathrm{Al}_{1-\mathrm{x}} \mathrm{Oy}$ thin films and they are in good agreement with the ratios calculated in the precursor solutions. Furthermore, EDS results confirmed $\mathrm{LaAlO}_{3}$ structures for stoichiometric (in the solution) $\mathrm{LaAlO}_{\mathrm{y}}$.

The dielectric properties of $\mathrm{La}_{\mathrm{x}} \mathrm{Al}_{1-\mathrm{x}} \mathrm{O}_{\mathrm{y}}$ films sandwiched between ITO and $\mathrm{Al}$ electrodes were investigated using a Wayne Kerr 6550B Precision Impedance Analyzer at frequencies in the range between $100 \mathrm{~Hz}$ and $10 \mathrm{MHz}$ applying a $60 \mathrm{mV}$ AC voltage. Figure 2(a) illustrates the dielectric constant and Nyquist plots (inset Figure 2(a)) of $\mathrm{Al}_{2} \mathrm{O}_{3}$, stoichiometric (in the solution) $\mathrm{LaAlO}_{\mathrm{y}}$ and $\mathrm{La}_{2} \mathrm{O}_{3}$. The geometric capacitances that were extracted from the Bode plots (not shown) were $46 \mathrm{nF} / \mathrm{cm}^{2}, 168 \mathrm{nF} / \mathrm{cm}^{2}$ and $147 \mathrm{nF} / \mathrm{cm}^{2}$ for $\mathrm{Al}_{2} \mathrm{O}_{3}(175 \mathrm{~nm})$, stoichiometric (in the solution) $\mathrm{LaAlO}_{\mathrm{y}}(83 \mathrm{~nm})$ and $\mathrm{La}_{2} \mathrm{O}_{3}(144 \mathrm{~nm})$ respectively. The dielectric constant variation as a function of the $\left[\mathrm{La}^{3+}\right] /\left[\mathrm{La}^{3+}+\mathrm{Al}^{3+}\right]$ ratio is also depicted in Figure 1(b).

The current-voltage density characteristics of MIM structures were also investigated. In the case of $\mathrm{LaAlO}_{\mathrm{y}}$ and $\mathrm{La}_{2} \mathrm{O}_{3}$ dielectrics, the leakage current density was found to be very low (less than $3 \mathrm{nA} / \mathrm{cm}^{2}$ at $1.5 \mathrm{MV} \mathrm{cm}^{-1}$, typical field of the related TFTs operation at saturation) and no breakdown voltage occurred for electric fields up to $5 \mathrm{MV} \mathrm{cm}^{-1}$. 
One can immediately observe is the monotonic increase of the static dielectric constant with increase in the lanthanum content that reaches a value of about 16 for the $\mathrm{LaAlO}_{y}$ and 24 for $\mathrm{La}_{2} \mathrm{O}_{3}$. The latter constitute the highest values for solution processed $\mathrm{La}_{2} \mathrm{O}_{3}$ and $\mathrm{LaAlO}_{\text {y }}$ ever reported. ${ }^{28,32}$ Additionally, Nyquist plots (inset Figure 1(a)) reveal stable stacks with excellent capacitive properties as evidenced from the equivalent circuit that consists of a large shunt and low series resistance.

The surface morphologies of $\mathrm{La}_{x} \mathrm{Al}_{1-\mathrm{x}} \mathrm{O}_{\mathrm{y}}$ films were investigated by atomic force microscopy (AFM). Atomic force microscopy images were taken in contact mode under ambient conditions using a MultiMode ${ }^{\mathrm{TM}}$ scanning probe microscope (MM-SPM) fitted to a Nanoscope IIIa controller unit employing a silicon tip of a radius $<10 \mathrm{~nm}$. Representative images of $\mathrm{Al}_{2} \mathrm{O}_{3}$, stoichiometric $\mathrm{LaAlO}_{\mathrm{y}}$ and $\mathrm{La}_{2} \mathrm{O}_{3}$ respectively are illustrated in Figure 3 . The measured root-mean-square (RMS) roughness of the surface $(1 \mu \mathrm{m} \times 1 \mu \mathrm{m})$ was found to be $\sim 1.77 \mathrm{~nm}, \sim 1.97$ and $\sim 2.52$ for $\mathrm{Al}_{2} \mathrm{O}_{3}$, stoichiometric (in the solution) $\mathrm{LaAlO}_{\mathrm{y}}$ and $\mathrm{La}_{2} \mathrm{O}_{3}$ respectively.

Such smooth dielectrics providing good interface properties between the dielectric and semiconducting channel are promising for the implementation of spray coated $\mathrm{La}_{\mathrm{x}} \mathrm{Al}_{1-\mathrm{x}} \mathrm{O}_{\mathrm{y}}$ films into TFT devices.

The microstructure of the $\mathrm{La}_{\mathrm{x}} \mathrm{Al}_{1-\mathrm{x}} \mathrm{O}_{\mathrm{y}}$ films were further characterized by $\mathrm{x}$-ray diffraction. Grazing incidence x-ray diffraction (GIXRD) experiments were performed using a Rigaku Ultima+ diffractometer with $\mathrm{CuK} \alpha$ radiation operating at $40 \mathrm{kV}$. The diffraction patterns of selected $\mathrm{La}_{x} \mathrm{Al}_{1-\mathrm{x}} \mathrm{O}_{\mathrm{y}}$ films on glass are depicted in Figure 4.

As evidenced from the diffraction patterns only pure $\mathrm{La}_{2} \mathrm{O}_{3}$ shows crystalline features whereas no obvious diffraction peaks related to $\mathrm{Al}_{2} \mathrm{O}_{3}$ or $\mathrm{LaAlO}_{3}$ were detected for the rest of $\mathrm{La}_{\mathrm{x}} \mathrm{Al}_{1-\mathrm{x}} \mathrm{O}_{\mathrm{y}}$ films indicating amorphous films. Analysis of the (400) diffraction peak of the 
pure $\mathrm{La}_{2} \mathrm{O}_{3}$ pattern using the Debye-Scherrer formula yields an average crystallite size of 30 $\mathrm{nm}$. Note that indexing of the $\mathrm{La}_{2} \mathrm{O}_{3}$ pattern is based on both the $\mathrm{La}_{2} \mathrm{O}_{3}$ cubic (ICDD 653185 ) and hexagonal (ICDD 05-0602) phases of $\mathrm{La}_{2} \mathrm{O}_{3}$ that seem to coexist in the film. As mentioned earlier, $\mathrm{La}_{2} \mathrm{O}_{3}$ is sensitive to environmental moisture and $\mathrm{CO}_{2}$. This is further evidenced by the diffraction pattern of $\mathrm{La}_{2} \mathrm{O}_{3}$ (Figure 4) where $\mathrm{La}(\mathrm{OH})_{3}$ (ICDD 06-0585), $\mathrm{La}_{2} \mathrm{CO}_{5}$ (ICDD 23-0320) and $\mathrm{La}_{2} \mathrm{O}_{2} \mathrm{CO}_{3}$ (ICDD 48-1113) reflections also contribute to the pattern.

The performance of $\mathrm{La}_{\mathrm{x}} \mathrm{Al}_{1-\mathrm{x}} \mathrm{O}_{\mathrm{y}}$ films as gate dielectrics was investigated in TFTs employing spray coated $\mathrm{ZnO}$ as the semiconducting channel. $\mathrm{ZnO}$ semiconducting channels were spray coated onto the $\mathrm{Al}_{2} \mathrm{O}_{3}$, a- $\mathrm{LaAlO}_{\mathrm{y}}$ and $\mathrm{La}_{2} \mathrm{O}_{3}$-coated ITO substrates heated at 400 ${ }^{\circ} \mathrm{C}$ from $25 \mathrm{mg} / \mathrm{mL}$ zinc acetate $\left(\mathrm{Zn}\left(\mathrm{CH}_{3} \mathrm{CO}_{2}\right)_{2}\right) \cdot 2 \mathrm{H}_{2} \mathrm{O}$ solutions in methanol until films of typical thickness of $\sim 35 \mathrm{~nm}$ were obtained. Bottom gate-top contact (BG-TC) transistors were fabricated by employing aluminum $(\mathrm{Al})$ source and drain $(\mathrm{S} / \mathrm{D})$ electrodes $(50 \mathrm{~nm})$ that were thermally evaporated under high vacuum $\left(10^{-6} \mathrm{mbar}\right)$ through a shadow mask on the spray coated glass/ITO/composite/ZnO stacks. To prevent $\mathrm{Al}$ oxidation and exposure of the $\mathrm{ZnO}$ channel to air's water vapors, the device characterization was performed under high vacuum $\left(10^{-6} \mathrm{mbar}\right)$, at room temperature. Electrical measurements were carried out using an Agilent B1500A semiconductor parameter analyzer. The electron mobility was extracted from the transfer characteristics in both the linear and saturation regimes using the gradual channel approximation. A representative set of transfer characteristics obtained from $\mathrm{ZnO}$ based TFTs $(\mathrm{L}=20 \mu \mathrm{m}, \mathrm{W}=1500 \mu \mathrm{m})$ employing $\mathrm{Al}_{2} \mathrm{O}_{3}$, stoichiometric a-LaAlO $\mathrm{y}$ and $\mathrm{La}_{2} \mathrm{O}_{3}$ gate dielectrics (with thickness of $\sim 175 \mathrm{~nm}, \sim 83 \mathrm{~nm}$ and $\sim 144 \mathrm{~nm}$ respectively) are illustrated in Figure 5(a). A set of output characteristics of the related $\mathrm{ZnO}$ TFT employing a-LaAlO 3 gate dielectric is also depicted in Figure 5(b). 
In general, ZnO-based TFTs employing $\mathrm{La}_{x} \mathrm{Al}_{1-\mathrm{x}} \mathrm{O}_{\mathrm{y}}$ gate dielectrics (Figure 5) exhibit excellent operating characteristics in terms of electron mobility of $\sim 12 \mathrm{~cm}^{2} \mathrm{~V}^{-1} \mathrm{~s}^{-1}$ and on/off current modulation ratios in the range between $\sim 10^{6}$ and $\sim 10^{7}$. One thing, however, that can be immediately observed is the upshift of the threshold/turn on voltage with increase of the lanthanum content. This upshift, in particular for the TFT employing $\mathrm{La}_{2} \mathrm{O}_{3}$ as the gate dielectric, may be attributed to the presence of empty electronic traps at the $\mathrm{La}_{2} \mathrm{O}_{3} / \mathrm{ZnO}$ interface. Similar behavior has already been reported for Indium Gallium Zinc Oxide (IGZO) semiconducting channels on $\mathrm{LaAlO}_{3}$ gate dielectrics. ${ }^{32}$ Analyses also reveal improved operation characteristics for the TFTs that employ a-LaAlO gate dielectrics as evidenced by the hysteresis-free operation and decreased subthreshold swing (SS) of $650 \mathrm{mV} \cdot \mathrm{dec}^{-1}$ (compared with $1000 \mathrm{mV} \cdot \mathrm{dec}^{-1}$ and $800 \mathrm{mV} \cdot \mathrm{dec}^{-1}$ for TFTs employing $\mathrm{Al}_{2} \mathrm{O}_{3}$ and $\mathrm{La}_{2} \mathrm{O}_{3}$ gate dielectrics respectively).

We have investigated the properties of $\mathrm{La}_{\mathrm{x}} \mathrm{Al}_{1-\mathrm{x}} \mathrm{O}_{\mathrm{y}}$ dielectrics as a function of the lanthanum to aluminum atomic ratio. The thin films were deposited by spray pyrolysis under ambient air at moderate substrate temperatures of $\sim 440{ }^{\circ} \mathrm{C}$ and were implemented as gate dielectrics in TFTs employing spray coated $\mathrm{ZnO}$ semiconducting channels. The $\mathrm{La}_{\mathrm{x}} \mathrm{Al}_{1-\mathrm{x}} \mathrm{O}_{\mathrm{y}}$ films were characterized using a wide range of techniques that revealed smooth $\mathrm{La}_{\mathrm{x}} \mathrm{Al}_{1-\mathrm{x}} \mathrm{O}_{\mathrm{y}}$ composites of amorphous phase, a wide band gap, and high dielectric constant. Stoichiometric a-LaAlO showed high dielectric constant, $k \sim 16$, wide band gap $\mathrm{E}_{\mathrm{g}} \sim 6.18 \mathrm{eV}$ and very low leakage currents $\left(<6 \mathrm{nA} / \mathrm{cm}^{2}\right.$ at $\left.\sim 3 \mathrm{MV} \mathrm{cm}^{-1}\right)$. ZnO-based TFTs employing stoichiometric a-LaAlO dielectrics showed excellent characteristics i.e. hysteresis-free operation, electron mobilities of $\sim 12 \mathrm{~cm}^{2} \mathrm{~V}^{-1} \mathrm{~s}^{-1}$, slightly improved compared to those employing solution processed $\mathrm{Al}_{2} \mathrm{O}_{3}$ $\left(\sim 10 \mathrm{~cm}^{2} \mathrm{~V}^{-1} \mathrm{~s}^{-1}\right)$ and $\mathrm{La}_{2} \mathrm{O}_{3}\left(\sim 11 \mathrm{~cm}^{2} \mathrm{~V}^{-1} \mathrm{~s}^{-1}\right)$ gate dielectrics, on/off current modulation ratio and subthreshold swing of $10^{6}$ and $650 \mathrm{mV} \mathrm{dec}^{-1}$ respectively. In addition, the excellent films uniformity and reproducibility over large areas combined with the TFTs stability under 
constant bias stress test (data not shown) indicates the potential for the rapid development of transparent oxide electronics at low manufacturing cost employing solution processing paradigms.

\section{Acknowledgements}

M.E. is grateful for support from the Ministry of Education Malaysia and Faculty of Electronic \& Computer Engineering, Universiti Teknikal Melaka, Malaysia (UTeM).

\section{Figure Captions}

Figure 1: (a) Tauc plots (b) Optical band gap and static dielectric constant and c) Urbach tail energy of $\mathrm{La}_{\mathrm{x}} \mathrm{Al}_{1-\mathrm{x}} \mathrm{O}_{\mathrm{y}}$ dielectrics as a function of the $\left[\mathrm{La}^{3+}\right] /\left[\mathrm{La}^{3+}+\mathrm{Al}^{3+}\right]$ atomic ratio. The asymmetric error bars refer to $\left[\mathrm{La}^{3+}\right] /\left[\mathrm{La}^{3+}+\mathrm{Al}^{3+}\right]$ obtained from Energy-dispersive X-ray spectroscopy measurements of selected samples. The solid lines are guide to the eye.

Figure 2: (a) Dielectric constant dispersions in the frequency range between $100 \mathrm{~Hz}$ and 10 $\mathrm{MHz}$ and Nyquist plots (inset) of spray pyrolysis deposited $\mathrm{Al}_{2} \mathrm{O}_{3}$, stoichiometric (in the solution) $\mathrm{LaAlO}_{\mathrm{y}}$ and $\mathrm{La}_{2} \mathrm{O}_{3}$ layers sandwiched between ITO and $\mathrm{Al}$ electrodes. (b) Leakage current density versus applied electric field of $\mathrm{Al}_{2} \mathrm{O}_{3}$, stoichiometric (in the solution) $\mathrm{LaAlO}_{\mathrm{y}}$ and $\mathrm{La}_{2} \mathrm{O}_{3}$ layers film deposited by spray pyrolysis in air. The arrows indicate the applied field of the related $\mathrm{ZnO}$-based TFTs operating at saturation.

Figure 3: AFM topography images (RMS roughness values are displayed in the inset) of solution processed of spray pyrolysis deposited (a) $\mathrm{Al}_{2} \mathrm{O}_{3}$, (b) stoichiometric (in the solution) $\mathrm{LaAlO}_{\mathrm{y}}$ and c) $\mathrm{La}_{2} \mathrm{O}_{3}$ layers on ITO coated glass. 
Figure 4: GIXRD patterns of selected $\mathrm{La}_{\mathrm{x}} \mathrm{Al}_{1-\mathrm{x}} \mathrm{O}_{\mathrm{y}}$ dielectrics deposited by $\mathrm{SP}$ on glass substrates. Indexing of the patterns (when applicable) is based on both the $\mathrm{La}_{2} \mathrm{O}_{3}$ cubic and hexagonal phases of $\mathrm{La}_{2} \mathrm{O}_{3}$. The red and blue arrows indicate contributions to the pattern due to $\mathrm{La}(\mathrm{OH})_{3}$ as well as $\mathrm{La}_{2} \mathrm{CO}_{5}$ and $\mathrm{La}_{2} \mathrm{O}_{2} \mathrm{CO}_{3}$ respectively.

Figure 5: (a) Transfer characteristics of bottom-gate, top-contact (inset: architecture employed) TFTs with channel width $\mathrm{W}=1500 \mu \mathrm{m}$ and channel length $\mathrm{L}=20 \mu \mathrm{m}$ employing spray coated $\mathrm{Al}_{2} \mathrm{O}_{3}\left(\mathrm{~V}_{\mathrm{DS}, \mathrm{SAT}}=8 \mathrm{~V}\right)$, stoichiometric a-LaAlO $\left(\mathrm{V}_{\mathrm{DS}, \mathrm{SAT}}=10 \mathrm{~V}\right)$ and $\mathrm{La}_{2} \mathrm{O}_{3}$ $\left(\mathrm{V}_{\mathrm{DS}, \mathrm{SAT}}=20 \mathrm{~V}\right.$ ) gate dielectrics (with capacitance of $\sim 46 \mathrm{nF} / \mathrm{cm}^{2}, \sim 168 \mathrm{nF} / \mathrm{cm}^{2}$ and $\sim 147$ $\mathrm{nF} / \mathrm{cm}^{2}$ respectively. (b) Output characteristics of $\mathrm{ZnO}$-based TFT employing spray coated stoichiometric a-LaAlO 3 gate dielectric.

\section{References}

1. M.-G. Kim, H. S. Kim, Y.-G. Ha, J. He, M. G. Kanatzidis, A. Facchetti, and T. J. Marks, J. Am. Chem. Soc.132, 10352 (2010).

2. H. Liu, J. Sun, Q. Tang, and Q. Wan, J. Phys. Chem. C, 114, 12316, (2010)

3. S. A. Campbell, H. S. Kim, D. C. Gilmer, B. He, T. Ma, and W. L. Gladfelter, IBM J. Res. Develop. 43, 383 (1999)

4. R. Engel-Herbert, Y. Hwang, J. Cagnon, and S. Stemmer, Appl. Phys. Lett. 95, 062908 (2009).

5. M. Balog, M. Schieber, M. Michman, and S. Patai, J. Electrochem. Soc. 126, 1203 (1979)

6. G. D. Wilk and R. M. Wallace, Appl. Phys. Lett. 74, 2854 (1999).

7. G. D. Wilk and R. M. Wallace, Appl. Phys. Lett. 76, 112 (2000).

8. S. T. Meyers, J. T. Anderson, D. Hong, C. M. Hung, J. F. Wager, and D. A. Keszler, Chem. Mater. 19, 4023, (2007).

9. M. Nieminen, M. Putkonen and L. Niinisto, Appl. Surf. Sci. 174, 155 (2001).

10. T. Gougousi, D. Niu, R. W. Ashcraft and G. N. Parsons, Appl. Phys. Lett. 83, 3543 (2003).

11. J. B. Cheng, A. D. Li, Q. Y. Shao, H. Q. Ling, D. Wu, Y. Wang, Y. J. Bao, M. Wang, Z. G. Liu and N. B. Ming, Appl. Surf. Sci. 233, 91 (2004).

12. D. Afouxenidis, R. Mazzocco, G. Vourlias, P. J. Livesley, A. Krier, W. I. Milne, O. Kolosov, and G. Adamopoulos, ACS Appl. Mater. Interfaces, 7, 7334 (2015).

13. X. B. Lu, Z. G. Liu, Y. P. Wang, Y. Yang, X. P. Wang, H. W. Zhou, and B. Y. Nguyen, J. Appl. Phys. 94, 1229 (2003).

14. S.-G. Lim, S. Kriventsov, T. N. Jackson, J. H. Haeni, D. G. Schlom, A. M. Balbashov, R. Uecker, P. Reiche, J. L. Freeouf, and G. Lucovsky, J. Appl. Phys. 91, 4500 (2002). 
15. L. F. Edge, D. G. Schlom, S. A. Chambers, E. Cicerrella, J. L. Freeouf, B. Holländer, and J. Schubert, Appl. Phys. Lett. 84, 726 (2004).

16. B. S. Lim, A. Rahtu, P. de Rouffignac and R. G. Gordon, Appl. Phys. Lett. 84, 3957 (2004).

17. L. Niinisto, M. Nieminen, J. Paivasaari, J. Niinisto, M. Putkonen, M. Nieminen, Phys. Status Solidi A 201, 1443 (2004).

18. M. Nieminen, M. Putkonen and L. Niinisto, Appl. Surf. Sci. 174, 155 (2001).

19. L. F. Edge and D. G. Schlom, S. A. Chambers, E. Cicerrella and J. L. Freeouf, B. Hollander and J. Schubert, Appl. Phys. Lett. 84, 5 (2004).

20. S. Gaillard, Y. Rozier, C. Merckling, F. Ducroquet, M. Gendry, G. Hollinger, Microelectronic Eng. 80, 146 (2005).

21. H. M. Christen, G. Eres, J. Phys.: Condens. Matter. 20, 264005 (2008).

22. C. M. Carlson, J. C. Price, P. A. Parilla, D. S. Ginley, D. Niles, R. D. Blaugher, A. Goyal, M. Paranthaman, D. M. Kroeger and D. K. Christen, Physica C 304, 82 (1998).

23. A. E. Lee, C. E. Platt, J. F. Burch, R. W. Simon, J. P. Goral and M. M. Aljassim, Appl. Phys. Lett. 57, 2019 (1990).

24. E. Sader, H. Schmid, K. Hradil, W Wersing, Supercond. Sci. Technol. 4, 371373 (1991).

25. A. D. Li, Q. Y. Shao, H. Q. Ling, J. B. Cheng, D. Wu, Z. G. Liu, N. B. Ming, C. Wang, H. W. Zhou, B. Y. Nguyen, Appl. Phys. Lett. 83, 3540 (2003).

26. A. C. Jones, P. R. Chalker, J. Phys. D: Appl. Phys. 36, 80 (2003).

27. T. D. Manning, Y. F. Loo, A. C. Jones, H. C. Aspinall, P. R. Chalker, J. F. Bickley, L. M. Smith and G. W. Critchlow, J. Mater. Chem. 15, 3384 (2005).

28. A. N. Meza-Rocha, E. Zaleta-Alejandre, J. G. Cabanas-Moreno, S. GallardoHernandez, Z. Rivera-Alvarez,a M. Aguilar-Frutis, and C. Falcony, ECS J. Solid State Sci. Technol. 3 (2), N1 (2014).

29. M. Esro, G. Vourlias, C. Somerton, W. I. Milne, and G. Adamopoulos, Adv. Funct. Mater. 25, 134 (2015).

30. G. Adamopoulos, S. Thomas, D. D. C. Bradley, M. A. McLachlan, T. D. Anthopoulos, Appl. Phys. Lett. 98, 123503 (2011).

31. G. Adamopoulos, S. Thomas, P. H. Wöbkenberg, D. D. C. Bradley, M. A. McLachlan, T. D. Anthopoulos, Adv. Mater. 23, 1894 (2011).

32. P. N. Plassmeyer, K. Archila, J. F. Wager, C. J. Page, ACS Appl. Mater. Interfaces 7, 1678 (2015).

33. S. S. Shoup, M. Paranthaman, D. B. Beach, E. D. Specht, R. K. Williams, J. Mater. Res.12, 1017 (1997).

34. M. F. Ng, M. J. Cima, J. Mater. Res. 12, 1306 (1997).

35. G. Adamopoulos, A. Bashir, W. P. Gillin, S. Georgakopoulos, M. Shkunov, M. A. Baklar, N. Stingelin, D. D. C. Bradley, T. D. Anthopoulos, Adv. Funct. Mater. 21, 525 (2011)

36. J. Robertson, Rep. Prog. Phys. 69, 327 (2006). 

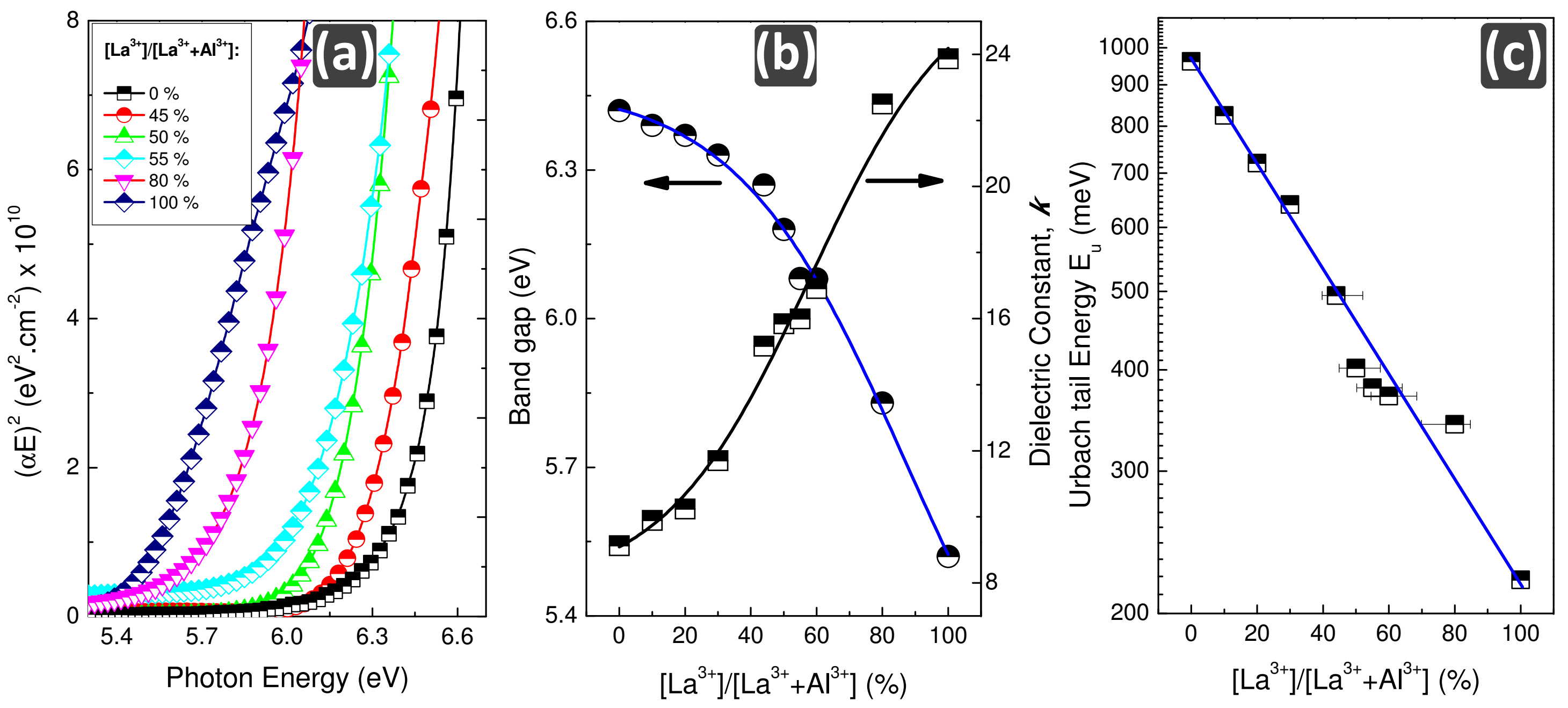

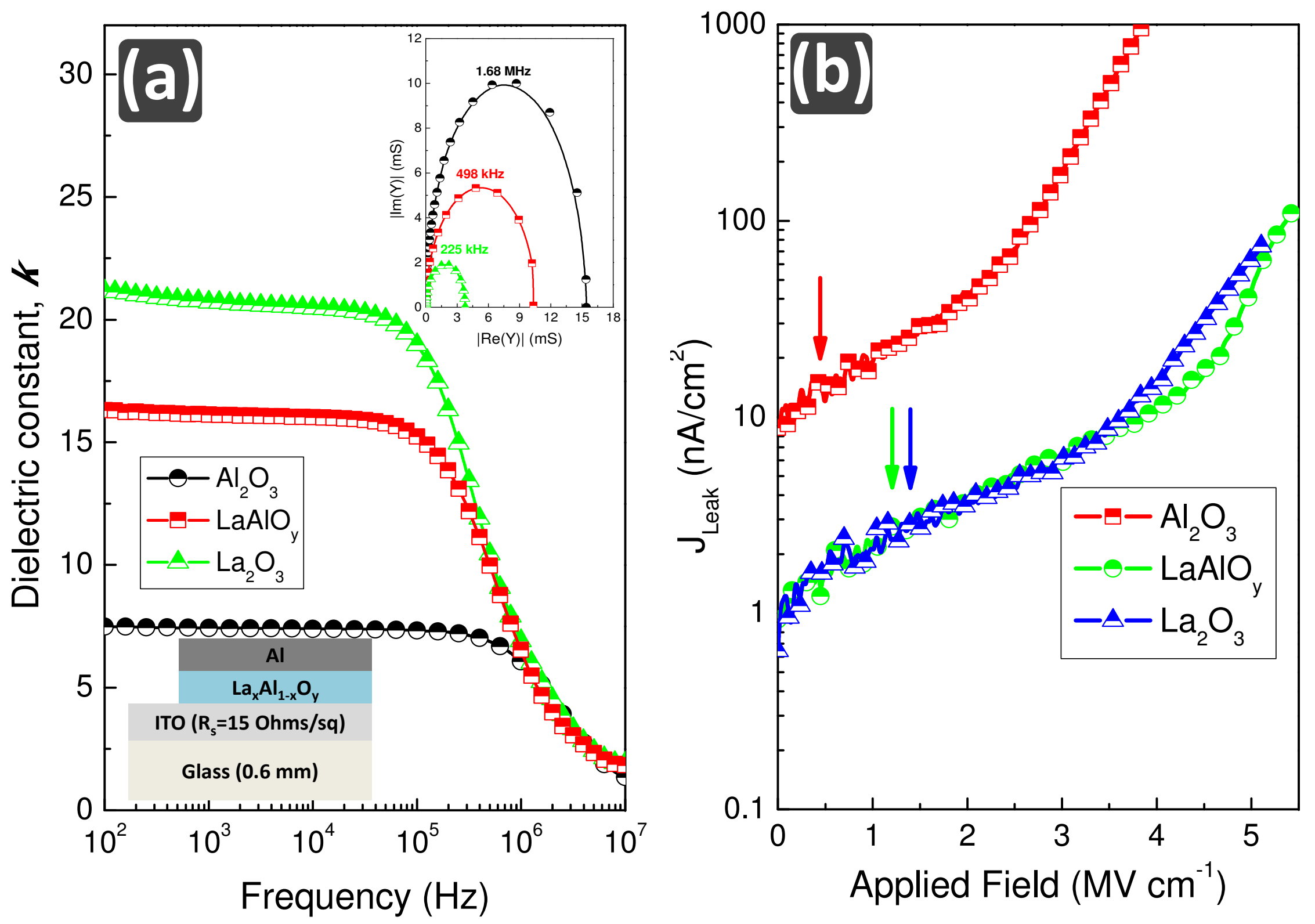

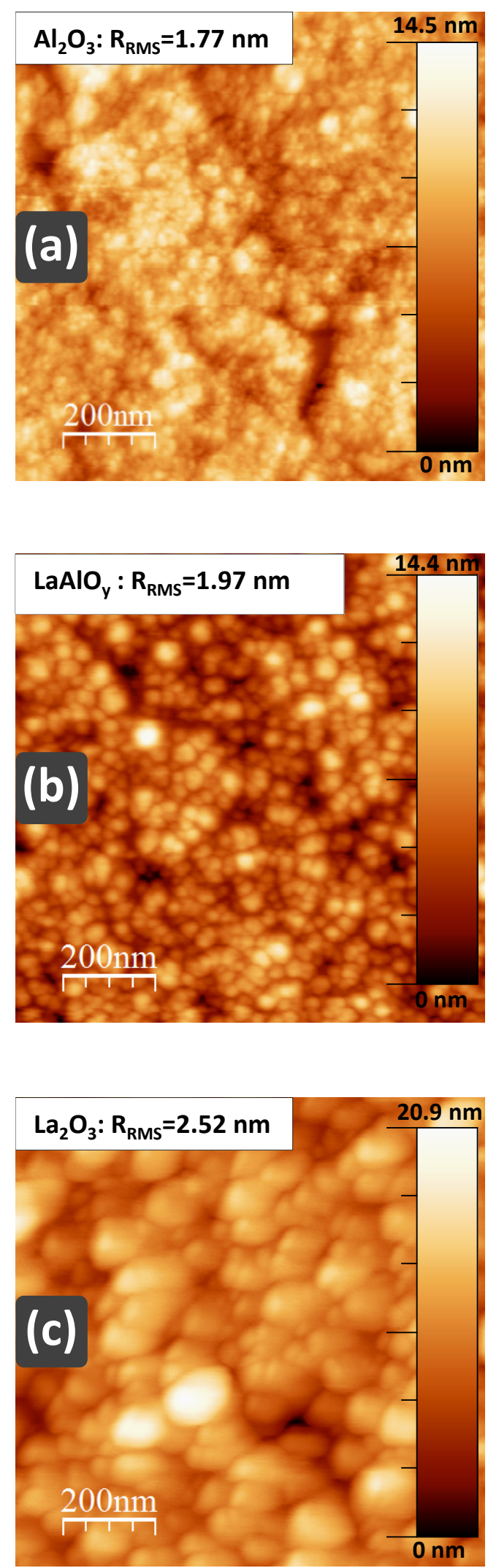


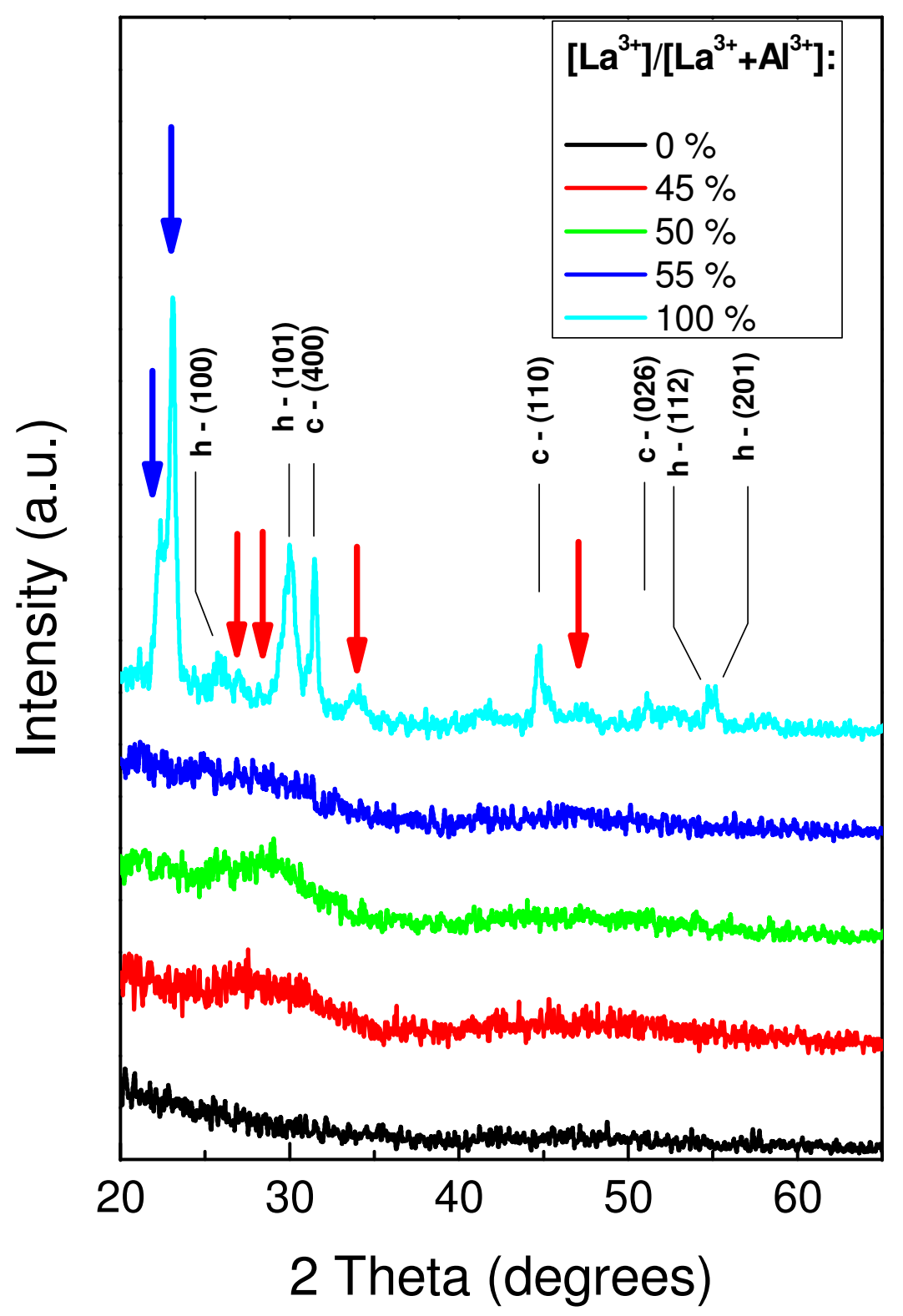



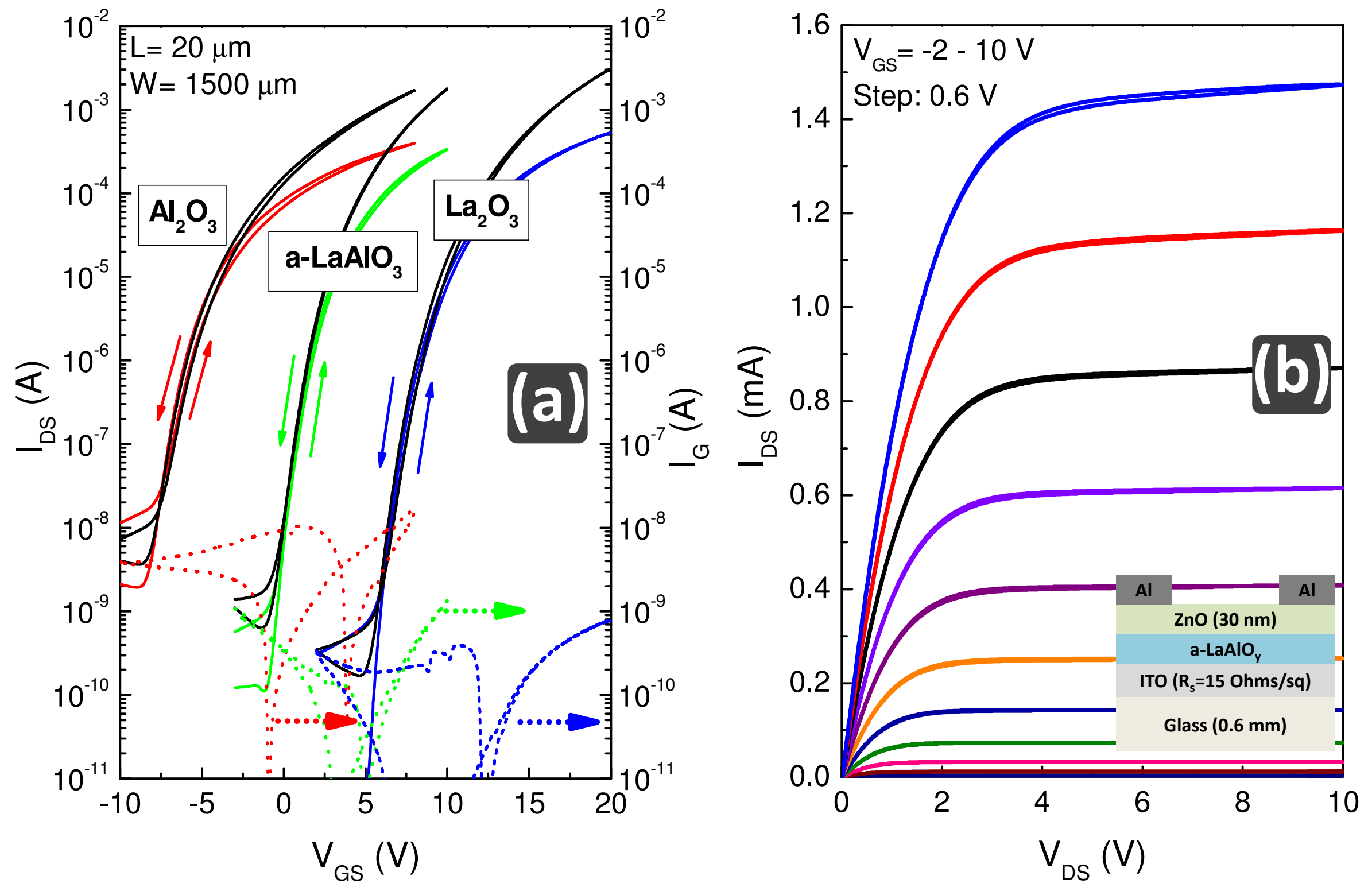